\title{
Traumatic Brain Injury and Its Effect on Learning English Language
}

\author{
Ibrahim Mahmoud Al Sabatin
}

\begin{abstract}
Over one million people suffer from a traumatic brain injury every year in the conflict areas and around the world, many of whom are students between the ages of 5 and 18.This study aims at investigating the effect of traumatic brain injury on learning English language. The sample of the study consists of 16 second grade children with a primary diagnosis of Traumatic Brain Injury (TBI). They were 16, 3 girls and 13 boys. This study tries to answer the following questions:

1- What is the effect of TBI on learning English as a foreign language?

2- What is the effect of TBI on pronouncing simple words?

3- What is the effect of TBI on writing simple words and simple sentences?

To achieve the purpose of the study, the researcher contacted families by phone, email or by a written form to obtain information about their children and to determine their general eligibility. Parents were asked whether the child had any history of language disorder, whether their child's TBI was secondary to another disorder or disability, specifically language. Parents also confirmed that the child was currently attending a private school or private institution. After the general procedures and aims of the study were explained, families interested in participating scheduled a testing time at their desired location. The Second step in the procedure is providing students with two different tests concerning learning English language, spoken and written tests. SPSS program was used to the run analyses.
\end{abstract}

Index Terms-Traumatic brain injury, effect, learning English language.

\section{INTRODUCTION}

Students who have sustained a traumatic brain injury (TBI) return to the school setting with a range of cognitive, psychosocial, and physical deficits that can significantly affect their academic functioning [1], Preventing School Failure. Successful educational reintegration for students with TBI requires careful assessment of each child's unique needs and abilities and the selection of classroom interventions designed to meet those needs. Most children who have sustained a traumatic brain injury (TBI), even a severe brain injury, will eventually return to a school or classroom setting following discharge from acute hospitalization. Some will return after only a brief hospitalization and others after a lengthy hospitalization and rehabilitation program [2]. Because the recovery process can take several months or even years, many of these children continue to have rehabilitation needs and cognitive impairments and will return to school while still in the recovery stages. It often becomes the

Manuscript received March 10, 2015; revised August 10, 2015.

Ibrahim Mahmoud Al Sabatin is with Hebron University, Palestine (e-mail: sabateenibrahim2002@yahoo.com). responsibility of the educational system to facilitate ongoing recovery and to provide needed services to help these children progress in their academic and social functioning. My purpose in this study is to review intervention strategies from recent research that are available to educators as they assist children with TBI when they return to the school environment. An intervention is defined as the systematic application of research-validated procedures to change behaviors through manipulation of antecedents and consequences or by teaching new skills [3]. Successful readjustment to school may require adaptation of the learning environment, acquisition or reacquisition of skills, provision of compensatory aids and strategies, as well as support services from special education providers.

\section{THE PURPOSE OF THE STUDY}

Our brain controls the way we act and feel, so an injury to the brain - usually an injury to the frontal lobe - causes changes in emotion and behavior. The life changes that happen after a TBI also affect how people act and feel. Traumatic brain injury can impact skills and functioning across cognitive, speech language physical and emotional lbehavioral domains. The degree to which are these impacted is the location and severity of the injury; however, even a mild concussion may have an impact on cognitive skills such as attention, learning and memory." Therefore, the purpose of this study is to investigate the effect of traumatic brain injury (TBI) on learning English as a foreign language.

\section{LITERATURE REVIEW}

This section is intended to provide theoretical and empirical rationale for the research questions of the present study. Initially, the researcher started with definition of the term TBI. Traumatic Brain Injury is a term used to describe acquired injuries to the brain [4]. The National Center for Injury Prevention and Control defines a TBI as "a bump, blow or jolt to the head or a penetrating head injury that disrupts the normal function of the brain" [5]. TBIs can happen many ways, but the most common causes of TBI for all age groups are falls, motor vehicle accidents, blows to the head, and assaults. The leading causes of TBI in children are falls and motor vehicle accidents, with all other categories representing the minority of TBI cases annually [6]. TBIs vary widely in severity and are typically measured using the Glasgow Coma Scale, which ranks head injuries on a scale from 3-15, with 3 being the most severe and 15 being the most mild. Traumatic brain injuries are categorized along a continuum of severity: severe, moderate, and mild injury - with the majority of 
injuries falling into the mild range. Although there are multiple factors and different grading systems used to classify these injuries, most use similar criteria. Many times, individuals with more severe injuries have more severe deficits, more residual long-term impairments, and a longer recovery course. Those with milder TBIs may have subtle problems that are never properly diagnosed. These categorizations are usually made early on in the course of injury and do not always correlate with the speed or extent of recovery from a TBI [7]. Medical records of TBIs generally reflect the level of care required to treat the injury, including emergency department visits, hospitalizations, and deaths. The majority of head injuries are measured as "mild" on the Glasgow Coma Scale; similarly, the majority of head injuries require only emergency department visits rather than extended hospitalizations [8].

TBI Under IDEA Children comprise the age group most likely to visit an emergency room following a head injury; they are also least likely to die from a TBI [9].

This translates into a large number of children who sustain a TBI and return to school with special needs that must be met due to changes in cognitive and behavioral abilities.

In 1975, the Education for All Handicapped Children Act was passed, and children with TBI could then be served in the special education system under the category "other health impaired" [10]. In 1990, the Individuals with Disabilities Education Act (IDEA; P.L. 101-476), was amended to include Traumatic Brain Injury as a specific disability category for special education (U.S. Department of Education, 1990).

\section{The CAUSES OF TRAUMATIC BRAIN INJURY}

The major causes of TBI are falls, motor vehicle accidents, blows to the head, and wars. Traumatic brain injury also results from penetrating wounds, severe blows to the head with shrapnel or debris, and falls or bodily collisions with objects following a blast. The degree of damage can depend on several factors, including the nature of the event and the force of impact (see Fig. 1).

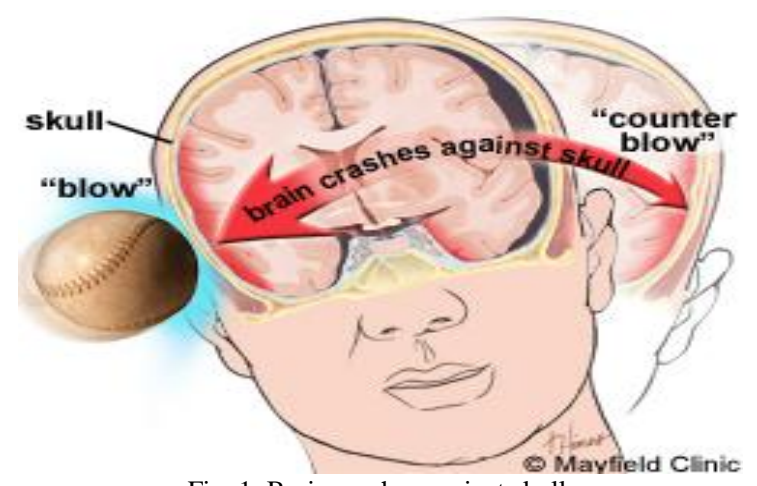

Fig. 1. Brain crashes against skull.

\section{EdUCATIONAL Limitations Following TBI}

Behavior Deficits. One of the educational limitations that can arise after a child sustains a TBI relates to change in behavior. TBI has been found to increase the likelihood of behavioral problems in the academic environment [11].
Children who have sustained a TBI have been observed to have difficulty: remaining focused on academic tasks, developing positive peer or teacher interactions, accepting their limitations, maintaining a consistent mood, controlling anger, accurately remembering events, accepting responsibility for their actions, saying things without thinking about consequences, waiting to begin working, appearing to be apathetic, being reluctant to engage in activities and engaging in incongruent emotional responses, [12].

Cognitive Deficits. In addition to behavioral concerns after a TBI, the child is likely to suffer from cognitive difficulties. Up to two-thirds of children who sustain a TBI will experience long-term difficulties with cognition [12]. Unfortunately, TBI appears to affect many facets of cognitive ability that results in a negative impact on academic performance.

The Rancho Los Amigos Levels of Cognitive Functioning (RLCF) is one of the best and most widely used ways of describing recovery from brain injury. The RLCF describes ten levels of cognitive (thinking) recovery. Research has shown that the speed at which a person progresses through the levels of the RLCF can predict how fully a person will recover.

Level 1 - No Response: Person appears to be in a deep sleep.

Level 2 - Generalized Response: Person reacts inconsistently and not directly in response to stimuli.

Level 3 - Localized Response: Person reacts inconsistently and directly to stimuli.

Level 4 - Confused/Agitated: Person is extremely agitated and confused.

Level 5 - Confused-Inappropriate/Non-agitated: Person is confused and responses to commands are inaccurate.

Level 6 - Confused-Appropriate: Person is confused and responds accurately to commands.

Level 7 - Automatic-Appropriate: Person can go through daily routine with minimal to no confusion.

Level 8 - Purposeful-Appropriate: Person has functioning memory, and is aware of and responsive to their environment.

Level 9 - Purposeful-Appropriate: Person can go through daily routine while aware of need for stand by assistance.

Level $10 \quad-\quad$ Purposeful-Appropriate/Modified Independent: Person can go through daily routine but may require more time or compensatory strategies.

\section{THE IMPACT OF TRAUMA ON LEARNING}

The damage to the hippocampus impairs the patient's ability to form new memories, thus affecting her ability to learn. Verbal learning can be affected, in which the patient has difficulty retaining information gathered from verbal sources, compared to visual. Another factor that affects learning after trauma is attention. Trauma can affect sustained and focused attention, though selective attention, which is used when processing sensory memories into short-term memories, is not affected [11]. The combination of the emotional problems from the trauma and the physiological damage can impair the child's performance in school, especially if she is not receiving psychological counseling [12]. When teaching a child with PTSD or another psychological disorder that is a 
result of trauma, coordinating lesson plans with a psychologist can help address the child's needs and difficulties.

\section{The COGNITIVE AND COMMUNICATION PROBLEMS THAT RESULT FROM TRAUMATIC BRAIN INJURY}

Cognitive and communication problems that result from traumatic brain injury vary from person to person. These problems depend on many factors which include an individual's personality, pre injury abilities, and the severity of the brain damage.

Cognitive functions refer to what or how much (e.g., How much does s/he know? What can s/he do? So long as the executive functions are intact, a person can sustain considerable cognitive loss and still continue to be independent, constructively self-serving, and productive.

When executive functions are impaired. the individual may no longer be capable of satisfactory self-care, of performing remunerative or useful work on his or her own, or of maintaining normal social relationships regardless of how well preserved are his or her cognitive capacities - or how high his or her scores on tests of skills, knowledge, and abilities.

Moreover, cognitive deficits usually involve specific functions or functional areas; impairment in executive functions tends to show up globally, affecting all aspects of behavior.

Executive functions consist of those capacities that enable a person to engage in independent, purposive, self-serving behavior successfully. They differ from cognitive functions in a number of ways. Questions about executive functions ask how or whether a person goes about doing something (e.g., Will s/he do it and, if so how?)

\section{PARTICIPANTS}

Participants in the present study were 16 second grade children with a primary diagnosis of Traumatic Brain Injury (TBI). They were 16, 3 girls and 13 boys. They live in Hebron and Bethlehem areas. They study at two different schools in Hebron and Bethlehem.

\section{RESEARCH QUESTIONS}

This study tries to answer the following questions:

1) What is the effect of TBI on learning English as a foreign language?

2) What is the effect of TBI on pronouncing simple words?

3) What is the effect of TBI on writing simple words and simple sentences?

\section{Study Procedures}

Pre-Screening. The researcher contacted families by phone, email or by a written form to obtain information about their children and to determine their general eligibility. Parents were asked whether the child had any history of language disorder, whether their child's TBI was secondary to another disorder or disability, specifically language. Parents also confirmed that the child was currently attending a private school or private institution. After the general procedures and aims of the study were explained, families interested in participating scheduled a testing time at their desired location.

The Second step in the procedure is providing students with two different tests concerning learning English language, spoken and written tests.

\section{DATA ANALYSiS}

The present study asked three research questions centered on the effect of TBI on learning English as a foreign language. SPSS program was used to the run analyses.

\section{RESUlTS}

The results of the study revealed the following:

1) There was a significant difference between Traumatic Brain Injury and students performance in pronouncing simple words.

2) There was a significant difference between Traumatic Brain Injury and student performance in writing simple words and sentences.

3) There was a significant difference between Traumatic Brain Injury and students performance in learning English Language.

In summary, it could be said that the language problems vary. Problems often include: word-finding difficulty, poor sentence formation and lengthy and often faulty descriptions or explanations. These are to cover for a lack of understanding or inability to think of a word. Many students have difficulty in understanding multiple meanings in jokes and figurative expressions such as, "A rolling stone gathers no moss" or "Take a flying leap."

Individuals with traumatic brain injuries are often unaware of their errors and can become frustrated or angry and place the blame for communication difficulties on the person to whom they are speaking. Reading and writing abilities are often worse than those for speaking and understanding spoken words. Simple and complex mathematical abilities are often affected. The speech produced by a person who has traumatic brain injury may be slow, slurred, and difficult or impossible to understand if the areas of the brain that control the muscles of the speech mechanism are damaged.

\section{DISCUSSION}

To compare the results of this study with similar studies concerning TBI and learning, students faced the same difficulties. In this study, students with TBI have problems in pronouncing and writing even short words. They are unable to pronounce short words correctly and they mix letters together. They are also unable to write short words and short sentences correctly. The results of the study revealed that there were significant differences between Traumatic Brain Injury and student performance in pronouncing simple words, in writing simple words and sentences, and in learning English Language in general. 
In summary, it could be said that Cognitive and communication problems that result from traumatic brain injury vary from person to person. These problems depend on many factors which include an individual's personality, pre injury abilities, and the severity of the brain damage. Teachers and educators play a key role in helping students with TBI succeed in their adjustment and reintegration into the school environment. The findings of this study make a notable contribution to the existing knowledge base regarding the early word decoding skills in young children with TBI, as well as the subskills, which may pose specific challenges in their early writing development. Importantly, children with TBI in the present study exhibited weak levels of alphabet knowledge, and some difficulties in phonemic awareness.

\section{RECOMMENDATIONS}

This study recommended developing programs that will facilitate a successful school reentry, educators must work together to develop a comprehensive plan based on each child's individual strengths and weaknesses. With careful planning, making needed adaptations to the learning environment, and using effective instructional aids and strategies to help children acquire new skills, most children can fortunately overcome many of these challenges and can experience success in their academic and social endeavors. Future research should expand on the work presented here to longitudinally examine the nature of these variables and their connections learning English language.

\section{REFERENCES}

[1] J. Bowen, W. R. Jenson, and E. Clark, School-Based Interventions for Students with Behavior Problems, Dec. 31, 2003.

[2] H. Klonoff and R. Paris, "Immediate, short-term and residual effects of acute head injuries in children: Neuropsychological and neurological correlates," Clinical Neuropsychology, pp. 179-210, 1974.

[3] S. Paris and A. Paris, "Assessments of early reading," in Handbook of Child Psychology, Child Psychology in Practice, W. Damon, M. Lerner, K. Renninger, and I. Sigel, Eds. 2006, pp. 48-74.
[4] P. B. Jantz and G. A. Coulter, "Child and adolescent traumatic brain injury: Academic, behavioral, and social consequences in the classroom," Support for Learning, vol. 22, no. 2, pp. 84-89, 2007.

[5] J. Langlois, W. Rutland-Brown, and K. Thomas, "Traumatic brain injury in the United States: Emergency department visits, hospitalizations, and deaths," National Center for Injury Prevention and Control, Atlanta, GA: Center for Disease Control and Prevention. 2004.

[6] G. Teasdale and B. Jennett, "Assessment of coma and impaired consciousness: A practical scale,” Lancet, vol. 2, pp. 81-84, 1974.

[7] L. Bullock, R. Gable, and J. Mohr, "Traumatic brain injury: A challenge for educators," Preventing School Failure, vol. 49, no. 4, pp. 6-10, 2005.

[8] H. W. Catts, M. E. Fey, X. Zhang, and B. J. Tomblin, "Estimating the risk of future reading difficulties in kindergarten children: A research-based model and its clinical," 2007.

[9] G. A. Coulter, "Child and adolescent traumatic brain injury," Academic, Behavioral, and Social Consequences in the Classroom, 2001.

[10] W. A. Hoover and P. B. Gough, "The simple view of reading." Reading and Writing: An Interdisciplinary Journal, vol. 2, pp. 127-160, 1990

[11] A. Hesketh, "Early literacy achievement of children with a history of speech problems," International Journal of Language and Communication Disorders, vol. 39, pp. 453-468, 2004.

[12] M. Hibbard, "Students with traumatic brain injury: Identification," Assessment and Classroom Accommodation, 2001.

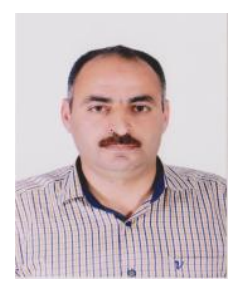

Ibrahim Sabatin lives in Hebron city, Palestine. He was born in Al-Arroub on October 17, 1971. He has a $\mathrm{PhD}$ degree in applied linguistics From Sudan University of Science and Technology.

$\mathrm{He}$ worked as an assistant Prof. of applied linguistics, in Arab American University, Hebron University, and Al Quds Open University, respectively. He also worked as the dean of College of Languages at American-Arabic Academy, druing 2010 to 2012. Now, he works for the Ministry of Education.

$\mathrm{He}$ participated in $10 \mathrm{local}$ and international conferences. He also published five publications in international conferences. Such as: "The effect of lexical and morpho-syntactic knowledge on reading comprehension in English language," Institute of Language and Communication Studies 2013; "Learning strategies and brain hemisphericity," Journal of Athens Institute for Education and Research, 2012; "The effect of cultural background knowledge on reading comprehension," Book of Proceedings, 2009.

Dr. Sabatin is a member at Palestinian Association of Teachers of English as a Foreign Language - PATEFL. 